\title{
A retrospective study assessing the clinical outcomes and costs of acute hepatitis A in Cape Town, South Africa
}

Jenna Patterson ${ }^{1,2^{*}}$, Susan Cleary ${ }^{3}$, Sheetal P. Silal ${ }^{4}$, Gregory D. Hussey ${ }^{2,5}$, Annabel Enoch ${ }^{6,7}$, Stephen Korsman ${ }^{6,7}$, Elizabeth Goddard ${ }^{8}$, Mashiko Setshedi ${ }^{9}$, Wendy C. Spearman ${ }^{9}$, Benjamin M. Kagina ${ }^{1,2}$ and Rudzani Muloiwa ${ }^{2,8}$

\begin{abstract}
Background: While some evidence has been demonstrated the cost-effectiveness of routine hepatitis A vaccination in middle-income countries, the evidence is still limited in other settings including in South Africa. Given this, the evidence base around the cost of care for hepatitis A needs to be developed towards considerations of introducing hepatitis A vaccines in the national immunisation schedule and guidelines.
\end{abstract}

Objectives: To describe the severity, clinical outcomes, and cost of hepatitis A cases presenting to two tertiary healthcare centers in Cape Town, South Africa.

Methods: We conducted a retrospective folder review of patients presenting with hepatitis A at two tertiary level hospitals providing care for urban communities of metropolitan Cape Town, South Africa. Patients included in this folder review tested positive for hepatitis A immunoglobulin M between 1 January 2008 and 1 March 2018.

Results: In total, 239 folders of hepatitis A paediatric patients $<15$ years old and 212 folders of hepatitis A adult patients $\geq 15$ years old were included in the study. Before presenting for tertiary level care, more than half of patients presented for an initial consultation at either a community clinic or general physician. The mean length of hospital stay was 7.45 days for adult patients and 3.11 days for paediatric patients. Three adult patients in the study population died as a result of hepatitis A infection and 29 developed complicated hepatitis A. One paediatric patient in the study population died as a result of hepatitis A infection and 27 developed complicated hepatitis A, including 4 paediatric patients diagnosed with acute liver failure. The total cost per hepatitis A hospitalisation was $\$ 1935.41$ for adult patients and $\$ 563.06$ for paediatric patients, with overhead costs dictated by the length of stay being the largest cost driver.

Conclusion: More than 1 in every 10 hepatitis A cases (13.3\%) included in this study developed complicated hepatitis $\mathrm{A}$ or resulted in death. Given the severity of clinical outcomes and high costs associated with hepatitis A hospitalisation, it is important to consider the introduction of hepatitis A immunisation in the public sector in South Africa to potentially avert future morbidity, mortality, and healthcare spending.

Keywords: Epidemiology, Health economics, Vaccine preventable disease, Immunization, Hepatology, Hepatitis A, Acute liver failure

\footnotetext{
*Correspondence: pttjen005@myuct.ac.za

${ }^{1}$ Division of Epidemiology and Biostatistics, School of Public Health and Family Medicine, University of Cape Town, Cape Town, South Africa Full list of author information is available at the end of the article
}

\section{Background}

The epidemiology of hepatitis A remains unclear globally. The World Health Organization (WHO) describes the epidemiology of hepatitis A according to hepatitis A 
virus (HAV) endemicity levels measured by the proportion of people with anti-HAV Immunoglobulin G (IgG) antibodies [1]. In areas where there is high exposure to the virus (high HAV endemicity), a large percentage of the population is assumed to have been asymptomatically infected by 10 years old [1]. Due to improvements in water, sanitation, and developments in socioeconomic status, low- and middle-income countries may transition from high to intermediate or low HAV endemicity. In areas of intermediate or low HAV endemicity, a lower proportion of the respective populations will have been infected during childhood, and the likelihood of symptomatic infection during adulthood increases [2]. In these cases, WHO recommends the consideration of introducing hepatitis A vaccines to reduce morbidity and mortality due to the disease [1].

Since 2005, there has been a documented shift in hepatitis A epidemiology in South Africa with a rise in the number of clinically symptomatic hepatitis A cases indicated by high anti-HAV Immunoglobulin $M$ (IgM) positivity rates, especially among children and adolescents $<15$ years old [2-5]. Analyses of routine HAV laboratory data between 2005 and 2015 in South Africa suggest that children $<5$ years old carry the largest burden of acute hepatitis A compared to other age groups. Additionally, these analyses point out that the seroprevalence of anti-HAV reaches levels $>90 \%$ only in individuals $>25$ years old, suggesting South Africa should be classified as a country with intermediate HAV endemicity.

Despite South Africa's intermediate HAV endemicity status, hepatitis A vaccines are not currently included in the National Expanded Programme on Immunisation (EPI) even as the cost-effectiveness of universal hepatitis $A$ vaccination is well documented in low and intermediate HAV endemicity regions such as Argentina, Brazil, Chile, and Mexico [6-8]. It has, therefore, become important to consider the local hepatitis A morbidity, mortality, and costs of care to bolster considerations of introducing the vaccine in South Africa.

\section{Methods}

\section{Aim}

The aim of this study is to describe the clinical severity and costs of care for hepatitis A cases presenting to two public sector tertiary healthcare centers in Cape Town, South Africa. The results of this study will be used together with other ongoing research to forecast the health impacts and cost-effectiveness of different hepatitis A vaccination strategies to be considered for inclusion in the EPI.

\section{Setting and participants}

We conducted a retrospective folder review of patients presenting with hepatitis A to two tertiary level hospitals providing care for urban communities of metropolitan Cape Town, South Africa. The hospitals included Red Cross War Memorial Children's Hospital $(\mathrm{RCH})$ serving paediatric patients $<15$ years old and Groote Schuur Hospital (GSH) serving adult patients $\geq$ 15 years old.

Patients included in this folder review were identified by flagging all positive hepatitis $\mathrm{A}$ immunoglobulin $\mathrm{M}$ (IgM) tests between 1 January 2008 and 1 March 2018 through the South African National Health Laboratory Services database. Once folder numbers corresponding to positive IgM tests were identified, patient folders were reviewed for inclusion eligibility. Patients with clinically confirmed hepatitis A and without evidence of concomitant hepatitis E infection were selected for inclusion in this study.

\section{Hepatitis A case definition}

Included cases needed to meet both the clinical description and laboratory confirmation of acute hepatitis A, as defined by the Centres for Disease Control and Prevention (CDC) [9].

- Clinical description: An acute illness with a discrete onset of any sign or symptom consistent with acute viral hepatitis and either a) jaundice, or b) elevated serum alanine aminotransferase (ALT) or aspartate aminotransferase (AST) levels. Symptoms of acute viral hepatitis include fever, headache, malaise, anorexia, nausea, vomiting, diarrhoea, and abdominal pain.

- Laboratory criteria: Positive sera identification of immunoglobulin M (IgM) antibody to the hepatitis A virus.

At the time of admission, evidence of acute liver injury was assessed through analysis of international normalised ratio (INR), elevated levels of alanine aminotransferase (ALT), aspartate aminotransferase (AST), alkaline phosphatase (ALP), and total bilirubin $[10,11]$. Patient clinical outcomes were classified as uncomplicated, complicated, or deceased within further analysis.

\section{Hepatitis A outcome definitions}

Complications included the development of relapsing hepatitis, prolonged cholestasis, acute liver failure, or had comorbidities that complicated care and recovery. 
- Relapsing hepatitis A was defined in all patients as being re-admitted for hepatitis A within 6 months of first admission.

- Prolonged cholestasis was defined in all patients with prolonged jaundice lasting longer than 14 days and conjugated bilirubin $>10 \mathrm{IU} / \mathrm{L}$.

- Acute liver failure in paediatric patients was defined as INR $\geq 1.5$ not corrected by vitamin $\mathrm{K}$ in the presence of clinical hepatic encephalopathy or INR $\geq 2.0$ regardless of the presence or absence of clinical hepatic encephalopathy $[10,12]$.

- Acute liver failure in adult patients was defined as hepatic encephalopathy and coagulopathy INR $\geq 1.5$, in patients without pre-existing cirrhosis, and an illness of $<26$ weeks duration [13].

\section{Data collection}

Data were extracted from folders and corresponding electronic records by a clinical registrar using a predesigned piloted data extraction form. The data extraction form was piloted using 50 patient folders before the start of the study. The following data elements were included in the data extraction form: demographic information, hepatitis A risk factors, hospital admission and discharge dates, clinical signs and symptoms of hepatitis A, bloods drawn, medicines and products used for case management, medicines prescribed at discharge, clinical outcome, and length of stay in varying hospital wards. In addition, data on the patient account were extracted from the folders to estimate the percentage of the cost of hepatitis A cases carried by the national governments as the ultimate fee payer for the included facilities.

During data extraction, study IDs were generated to identify patients so that names and/or any patient identifying information were not included in the data extraction process. Data were analysed in STATA version 16.0 [14]. Clinical characteristics, demographics, and clinical variables were summarised using descriptive statistics. Means, medians, and interquartile ranges were calculated for continuous variables, while counts and percentages were calculated for categorical variables.

All study data were subsequently removed from Kobo Toolbox and have been saved on a password-protected hard drive which will be kept by the first author for 5 years. The study was approved by the University of Cape Town's Research Ethics Committee and research clearance was granted by GSH (HREC 485) and RCH's Research Committees (RCC 153).

\section{Costing}

Costing for hepatitis A cases was conducted following recommendations for conducting and reporting of economic evaluations as per the CHEERS guidelines [15]. To estimate the cost of care for hepatitis A cases, this study calculated the mean cost per hepatitis A hospitalisation from a health care provider's perspective. Costing of hepatitis A cases entailed the multiplication of counts of health service utilisation against unit costs. Counts of service utilisation were achieved using data extracted from folders. Thereafter, unit costs were established using a combination of the ingredients and step-down methods, as appropriate. In this process, the ingredients approach was first applied to cost the items directly used for the diagnosis and treatment of hepatitis A cases, including laboratory investigations, procedures, medications, and blood products [16]. Laboratory and blood unit costs were provided by the National Health Laboratory Services. Medicine unit costs were obtained from the 2018 National Tender Price List [17]. Radiology and other imaging investigation costs were derived from the 2018 National Uniform Patient Fee Schedule [18].

Overhead resources that could not be costed from the folder review were costed using the step-down approach. In the step-down approach, overhead expenditures were established from facility accounting records and were allocated to routine patient activity data to establish an overhead cost per inpatient day.

All costs were expressed in September 2018 prices and converted to US dollars using an average exchange rate over the same period (US $\$ 1=14.75$ South African Rand) [19]. One-way deterministic sensitivity analyses were conducted on the three largest patient-specific cost components including blood tests, medicines, and radiology tests to explore the impact on the mean cost per hepatitis A hospitalization. Each component was varied using the $90 \% \mathrm{CI}$ and the results are displayed in tornado diagrams.

\section{Results}

\section{Demographics and risk factor characteristics of the study population}

In total, 239 folders of hepatitis A paediatric patients $<15$ years old (median $=6.6$ years old) and 212 folders of hepatitis A adult patients $\geq 15$ years old (median $=27.4$ years old) were included in the study. A total of 8 adult patients and 6 paediatric patients included in the study were confirmed as HIV positive. Five adult patients and one paediatric patient were also positive for hepatitis B surface antigen (HBs-Ag), while one adult patient was also positive for hepatitis C. For patients where this information was reported, regular use of toilets without plumbing and sharing of communal taps were the most frequent hepatitis A risk factors among both adult and paediatric patients. The demographic and risk factor characteristics of the patients are further summarised in Table 1. 
Table 1 Demographics and risk factors for hepatitis A patients among the study patient population

\begin{tabular}{|c|c|c|}
\hline Variable & $\begin{array}{l}\text { Number of adult } \\
\text { patients }(\%)\end{array}$ & $\begin{array}{l}\text { Number of } \\
\text { paediatric } \\
\text { patients } \\
(\%)\end{array}$ \\
\hline Number of patients & 212 & 239 \\
\hline Median age (interquartile range) & $27.4(21.5,34.3)$ & $6.6(4.4,8.9)$ \\
\hline \multicolumn{3}{|l|}{ Gender } \\
\hline Female & $94(44.3 \%)$ & $125(52.3 \%)$ \\
\hline Male & $118(55.7 \%)$ & $114(47.7 \%)$ \\
\hline \multicolumn{3}{|l|}{ Patient account class } \\
\hline Patient pays nominal fees & $169(79.7 \%)$ & $194(81.2 \%)$ \\
\hline Patient pays a portion of fees & $12(5.7 \%)$ & $24(10.0 \%)$ \\
\hline Patient pays fees in full & $22(10.4 \%)$ & $14(5.9 \%)$ \\
\hline Not recorded & $9(4.2 \%)$ & $7(2.9 \%)$ \\
\hline Known contact with hepatitis A case & $20(9.4 \%)$ & $16(6.7 \%)$ \\
\hline \multicolumn{3}{|l|}{ Housing } \\
\hline Informal housing & $9(4.3 \%)$ & $9(3.8 \%)$ \\
\hline Formal housing & $9(4.3 \%)$ & $48(20.1 \%)$ \\
\hline Housing type not reported & $194(91.5 \%)$ & $182(76.1 \%)$ \\
\hline \multicolumn{3}{|l|}{ Water source } \\
\hline $\begin{array}{l}\text { Water source from outside dwell- } \\
\text { ing }\end{array}$ & $11(5.2 \%)$ & $58(24.3 \%)$ \\
\hline Water source not reported & $201(94.8 \%)$ & $181(75.7 \%)$ \\
\hline \multicolumn{3}{|l|}{ Sanitation } \\
\hline Toilet without plumbing & $19(9.0 \%)$ & $56(23.44 \%)$ \\
\hline Toilet type not reported & $193(91.0 \%)$ & $183(76.6 \%)$ \\
\hline \multicolumn{3}{|l|}{ Additional risk factors* } \\
\hline Alcohol use & $46(21.7 \%)$ & - \\
\hline IV drug use & $20(9.4 \%)$ & - \\
\hline Travel history & $10(4.7 \%)$ & 7 (3.0\%) \\
\hline
\end{tabular}

All variables are presented as $\mathrm{N}(\%)$

* Additional risk factor information including alcohol and IV drug use was not collected for paediatric patients

\section{Clinical presentation and severity}

Clinical signs and symptoms of hepatitis A at the time of admission are summarised in Table 2. More than half of patients in the study reported vomiting and abdominal pain as symptoms of hepatitis A before presentation for care at respective facilities. More than half of adult patients presented for care with clinical signs of jaundice, while more than half of paediatric patients presented for care with clinical signs of jaundice and enlargement of the liver. As displayed in Table 3, > 80\% of adult patients and $>90 \%$ of paediatric patients who developed complicated hepatitis A displayed evidence of acute liver injury at the time of admission. All patients who died from hepatitis A infection displayed evidence of prolonged INR at the time of admission.
Table 2 Hepatitis A clinical presentation

\begin{tabular}{lrr}
\hline Variable & $\begin{array}{l}\text { Number of adult } \\
\text { patients (\%) }\end{array}$ & $\begin{array}{l}\text { Number of } \\
\text { paediatric } \\
\text { patients } \\
\text { (\%) }\end{array}$ \\
\hline Prevalence of clinical symptoms & & \\
$\quad$ Abdominal pain & $110(51.9 \%)$ & $121(50.6 \%)$ \\
Anorexia & $58(27.4 \%)$ & $90(37.7 \%)$ \\
Dark urine & $83(39.2 \%)$ & $105(43.9 \%)$ \\
Diarrhea & $26(12.3 \%)$ & $62(25.9 \%)$ \\
Drowsiness & $4(1.9 \%)$ & $16(6.7 \%)$ \\
Fatigue & $49(23.1 \%)$ & $37(15.5 \%)$ \\
Fever $\geq 38^{\circ} \mathrm{C}$ & $68(32.1 \%)$ & $71(29.7 \%)$ \\
Headache & $21(9.9 \%)$ & $15(6.3 \%)$ \\
Jaundice & $155(73.1 \%)$ & $198(82.9 \%)$ \\
Joint ache & $8(3.8 \%)$ & $0(0.0 \%)$ \\
Nausea & $84(39.6 \%)$ & $20(8.4 \%)$ \\
Pale stool & $15(7.1 \%)$ & $13(5.4 \%)$ \\
Pruritis & $103(48.6 \%)$ & $58(24.3 \%)$ \\
Respiratory symptoms & $10(4.7 \%)$ & $22(9.2 \%)$ \\
Vomiting & $140(66.0 \%)$ & $166(69.5 \%)$ \\
Prevalence of clinical signs & & $137(57.3 \%)$ \\
Enlarged liver & $60(28.3 \%)$ & $105(43.9 \%)$ \\
Upper-right abdominal tender- & $104(49.1 \%)$ & \\
ness & & \\
& & \\
\hline
\end{tabular}

\section{Clinical outcomes}

Among the study population, 4 patients $(0.9 \%)$ died as a result of hepatitis A infection [GSH 3/212 (1.4\%); RCH $1 / 239(0.4 \%)]$. In addition to these deaths, 56 patients (12.4\%) developed complicated hepatitis A [GSH 29/212 (13.7\%); RCH 27/239 (11.3\%)]. Of the 14 HIV + patients included in the study, 7 of these patients (50\%) developed complicated hepatitis. One adult patient and two paediatric patients developed relapsing hepatitis A. Four paediatric patients developed prolonged cholestasis. Four paediatric patients and one adult patient included in this study developed acute liver failure from hepatitis A infection. One of these paediatric acute liver failure patients died during hospitalisation, however, no ALF patients in the study population were sent for transplant.

\section{Hepatitis A patient clinical service utilisation}

Before presenting for tertiary level care, 332 patients (73.6\%) [GSH 149/212 (70.3\%); RCH 183/239 (76.6\%)] presented for an initial consult at either a community health center, clinic, or general physician (Fig. 1). Following presentation for care at the primary level, the mean time for adults to present to GSH tertiary clinic or emergency room was $34.3 \mathrm{~h}$ (median $=17.1 \mathrm{~h}$ ) and the mean time for paediatric patients to present to 
Table 3 Hepatitis A clinical outcomes and evidence of acute liver injury

\begin{tabular}{|c|c|c|c|c|}
\hline \multicolumn{5}{|l|}{ Adult patients } \\
\hline Evidence of acute liver injury & All patients $(\mathrm{N}=212)$ & $\begin{array}{l}\text { Uncomplicated hepatitis } \\
(n=180,84.9 \%)\end{array}$ & $\begin{array}{l}\text { Complicated hepatitis A } \\
(n=29,13.7 \%)\end{array}$ & $\begin{array}{l}\text { Deceased } \\
(n=3 \\
1.4 \%)\end{array}$ \\
\hline $\mathrm{INR} \geq 1.5$ & $12(5.6 \%)$ & $9(5.0 \%)$ & $0(0.0 \%)$ & $3(100.0 \%)$ \\
\hline $\mathrm{ALT}>40 \mathrm{U} / \mathrm{L}$ & 199 (93.9\%) & $168(93.3 \%)$ & $27(93.1 \%)$ & $3(100.0 \%)$ \\
\hline $\mathrm{AST}>40 \mathrm{U} / \mathrm{L}$ & $197(92.9 \%)$ & $168(93.3 \%)$ & $26(89.7 \%)$ & $3(100.0 \%)$ \\
\hline$A L P>128 \mathrm{U} / \mathrm{L}$ & $192(90.6 \%)$ & $165(91.7 \%)$ & $24(82.8 \%)$ & $3(100.0 \%)$ \\
\hline Total bilirubin > $21 \mathrm{U} / \mathrm{L}$ & $188(88.7 \%)$ & $160(88.9 \%)$ & $25(86.2 \%)$ & $3(100.0 \%)$ \\
\hline \multicolumn{5}{|l|}{ Paediatric patients } \\
\hline Evidence of acute liver injury & All patients $(\mathrm{N}=239)$ & $\begin{array}{l}\text { Uncomplicated hepatitis } \\
(\mathrm{n}=211,88.3 \%)\end{array}$ & $\begin{array}{l}\text { Complicated hepatitis A } \\
(\mathrm{n}=27,12.8 \%)\end{array}$ & $\begin{array}{l}\text { Deceased } \\
(\mathrm{n}=1, \\
0.4 \%)\end{array}$ \\
\hline INR 1.50-1.99 & $9(3.8 \%)$ & $8(3.8 \%)$ & $1(3.7 \%)$ & $0(0.0 \%)$ \\
\hline$I N R \geq 2.0$ & $4(1.7 \%)$ & $0(0.0 \%)$ & $3(11.1 \%)$ & $1(100.0 \%)$ \\
\hline $\mathrm{ALT}>40 \mathrm{U} / \mathrm{L}$ & $239(100.0 \%)$ & $211(100.0 \%)$ & $27(100.0 \%)$ & $1(100.0 \%)$ \\
\hline $\mathrm{AST}>40 \mathrm{U} / \mathrm{L}$ & $238(99.6 \%)$ & $211(100.0 \%)$ & $26(96.3 \%)$ & $1(100.0 \%)$ \\
\hline $\mathrm{ALP}>128 \mathrm{U} / \mathrm{L}$ & $233(97.5 \%)$ & $207(98.1 \%)$ & $25(92.6 \%)$ & $1(100.0 \%)$ \\
\hline Total bilirubin > $21 \mathrm{U} / \mathrm{L}$ & $232(97.1 \%)$ & $206(97.6 \%)$ & 25 (92.6\%) & $1(100.0 \%)$ \\
\hline
\end{tabular}

All variables are presented as $\mathrm{N}(\%)$

ALT alanine aminotransferase, $A S T$ alanine aminotransferase, $U / L$ units per liter

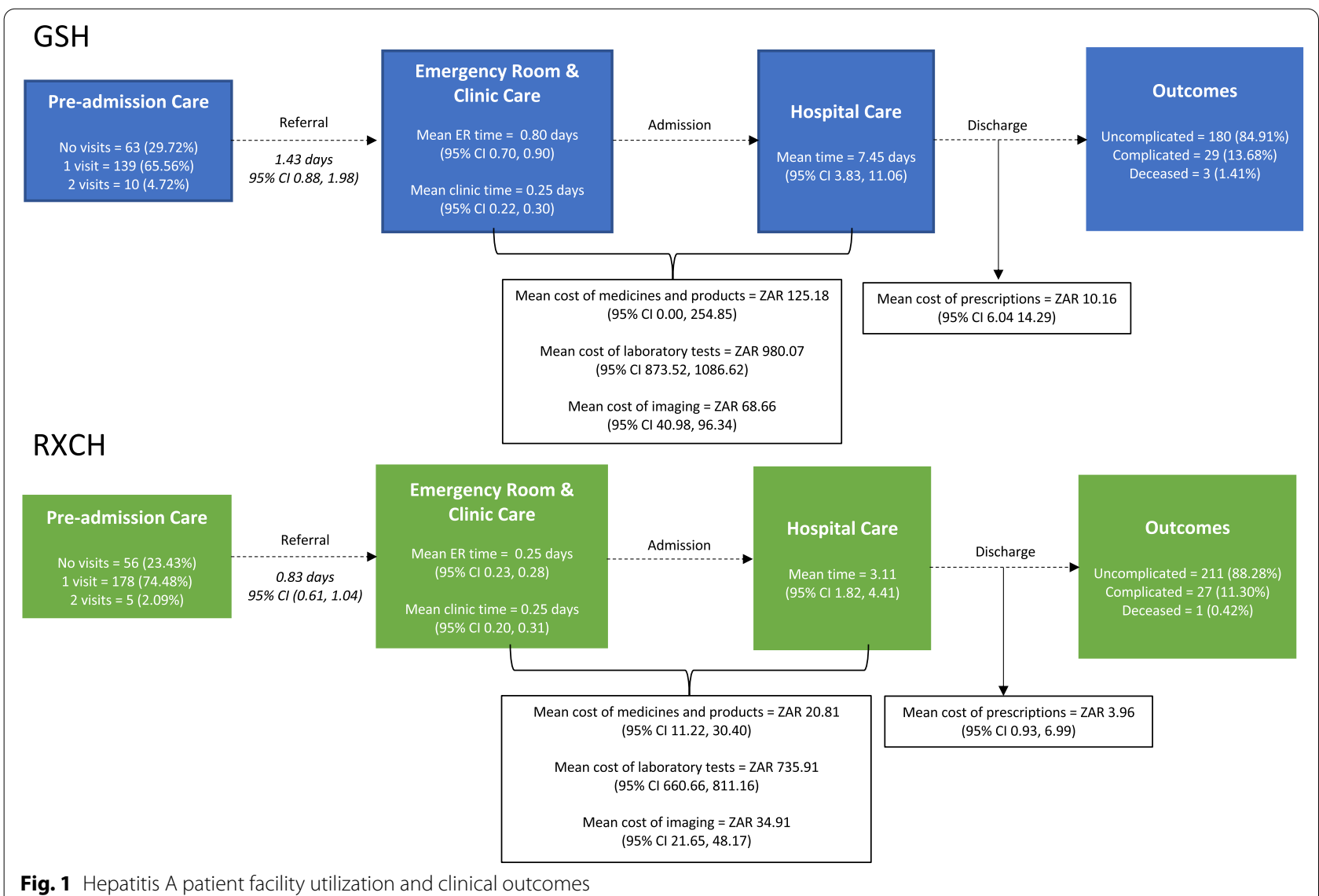

Fig. 1 Hepatitis A patient facility utilization and clinical outcomes 
$\mathrm{RCH}$ tertiary level clinic or emergency room was $20.0 \mathrm{~h}$ (median $=17.0 \mathrm{~h}$ ). The mean times spent in the emergency room or outpatient consulting ro in the teritiary hospital prior to admission for adult patients were $6 \mathrm{~h}$ $($ median $=6.2 \mathrm{~h}$ ) and $19.2 \mathrm{~h}$ (median $=6.2 \mathrm{~h}$ ), respectively. The mean times spent in the tertiary facility clinic and emergency rooms before hospital admission for paediatric patients were $6 \mathrm{~h}$ (median $=5.5 \mathrm{~h}$ ) and $6 \mathrm{~h}($ median $=4.7 \mathrm{~h})$, respectively. The mean length of inpatient hospital stay was 7.45 days (median $=0.8$ days) for adult patients and 3.11 days (median $=0.3$ days) for paediatric patients, which was largely influenced by the clinical outcome as displayed in Fig. 2 and Additional file 1: Table S1.

\section{Hepatitis A costing}

Using 2018 financial reports for each of the included facilities, overhead costs are presented in Table 4.

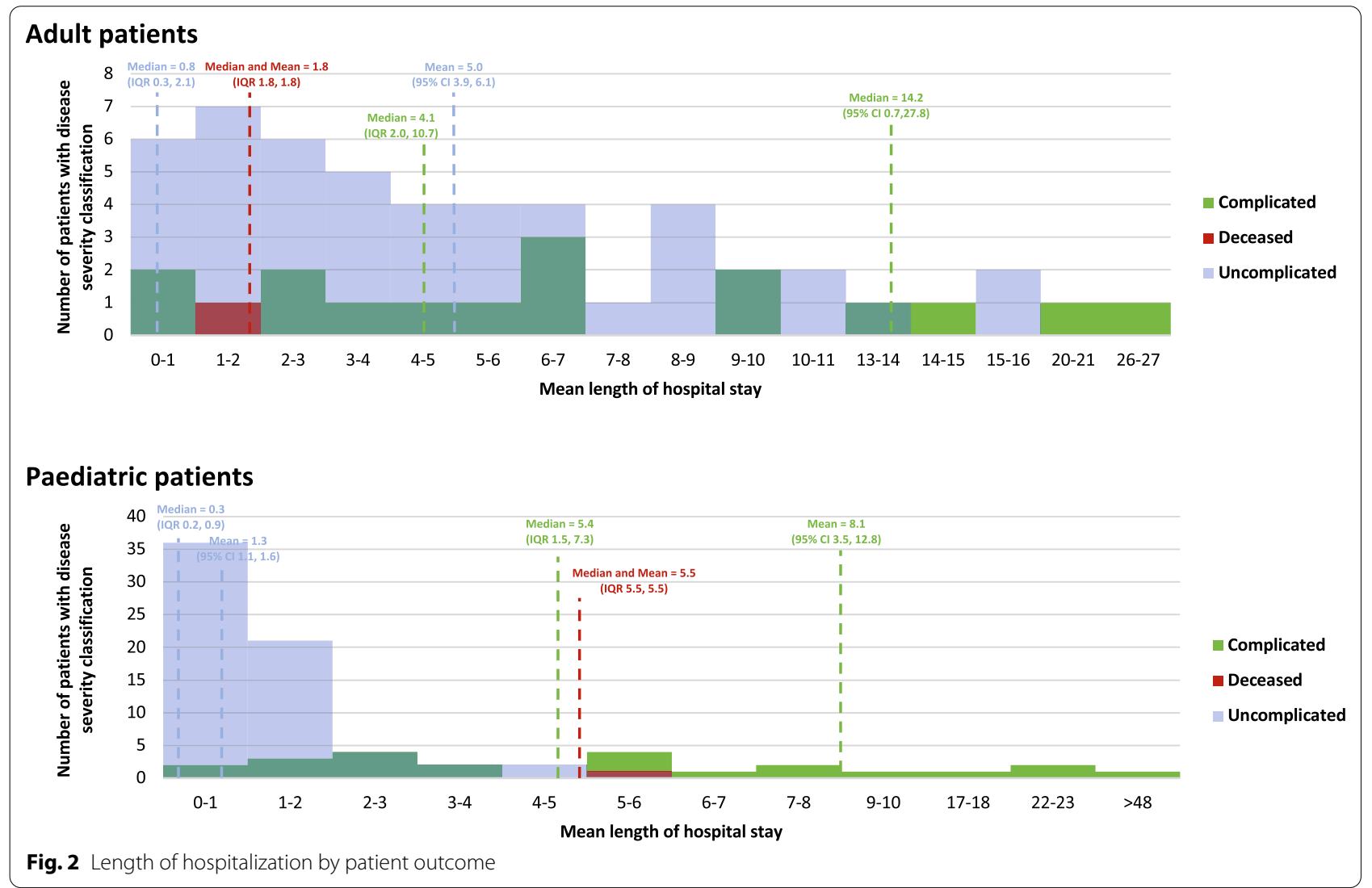

Table 4 Cost per patient day equivalent at included facilities in USD

\begin{tabular}{lll}
\hline Overhead line item & $\begin{array}{l}\text { Groote Schuur Hospital serving adult } \\
\text { patients }\end{array}$ & $\begin{array}{l}\text { Red Cross Children's War Memorial } \\
\text { Hospital serving paediatric } \\
\text { patients }\end{array}$ \\
\hline Compensation of employees & $\$ 119,892,542.40$ & $\$ 9,548,135.59$ \\
Employee benefits & $\$ 556,000.00$ & $\$ 175,457.63$ \\
Goods and services & $\$ 27,203,728.81$ & $\$ 9,441,423.73$ \\
Machinery and equipment & $\$ 1,715,050.85$ & $\$ 878,983.05$ \\
Software and intangible equipment & $\$ 16,949.15$ & $\$ 0.00$ \\
Total overhead costs & $\$ 149,384,271.20$ & $\$ 20,044,000.00$ \\
Total patient days & 599,931 & 122,439 \\
Overhead cost per patient day equivalent* & $\$ 249.00$ & $\$ 163.71$
\end{tabular}

\footnotetext{
* To obtain the cost per patient day equivalent, the total overhead costs were divided by the total patient days per facility
} 
Disaggregated expenditures in Table 4 and the patient volumes reported per facility in 2018 yielded a cost per patient day equivalent of $\$ 249.00$ for GSH and $\$ 163.71$ for $\mathrm{RCH}$.

The mean patient-specific hepatitis A costs including investigations, radiology, and medication were estimated to be $\$ 80.34$ (95\% CI $68.83,91.86)$ for adult patients and $\$ 53.94$ (95\% CI 48.81, 59.07) for paediatric patients (Table 5). Additional file 2: Table S2 provides detail on the utilisation and unit costs of the investigations, radiology, and medicines and products. The most expensive blood and radiological tests conducted in these patient groups were antibody tests (\$8.96) and gastroscopies (\$74.92). The most expensive medicines and products were fresh frozen plasma for adult patients $(\$ 618.97)$ and prescriptions at discharge (\$13.52) for paediatric patients.

Using $95 \%$ CIs, sensitivity analyses were conducted to explore changes in the mean cost per admission associated with the three largest components of the patientspecific hepatitis A costs (blood tests, medicines, and radiology). Results are presented using tornado diagrams for adult and paediatric patients in Figs. 3 and 4,

Table 5 Hepatitis A patient-specific costs per hospitalisation at facilities in USD

\begin{tabular}{lcc}
\hline Patient-specific cost & $\begin{array}{l}\text { Mean adult cost in } \\
\text { USD }(\mathbf{9 5 \%} \mathbf{C l})\end{array}$ & $\begin{array}{l}\text { Mean paediatric } \\
\text { cost in USD }(\mathbf{9 5 \%} \\
\mathbf{C I})\end{array}$ \\
\hline Laboratory tests & $66.45(59.2,73.7)$ & $49.89(44.79,55.0)$ \\
Radiology & $4.65(2.8,6.5)$ & $2.37(1.47,3.3)$ \\
Medications & $9.24(0.5,18.0)$ & $1.68(0.99,2.4)$ \\
Total & $80.34(68.8,91.9)$ & $53.94(48.8,59.1)$ \\
\hline
\end{tabular}

respectively. As displayed in these tornado plots, blood tests were the main cost driver for patient-specific hepatitis A costs in both adult and paediatric patients. Given the mean lengths of hospital stay for adult patients (7.45 days) and paediatric patients (3.11 days), the mean total cost per hepatitis A hospitalisation was $\$ 1935.41$ for adult patients and $\$ 563.06$ paediatric patients. The overhead costs dictated by the length of hospital stay were the main driver of total cost per hepatitis A hospitalisation as depicted in Fig. 5.

\section{Discussion}

The results of this study indicate that hepatitis A causes severe disease in adults and children with $13.3 \%$ of the study population having suffered death (4 patients) or complication (56 patients). Of the patients who developed complications, almost all displayed evidence of acute liver injury at the time of admission. Of the patients who were HIV positive (14 patients), half developed complications due to hepatitis A infection. None of the acute liver failure patients included in this study population were referred for a liver transplant. To qualify for a transplant, social and socioeconomic criteria are used exclusion criteria for patients as transplant requires adherence to lifelong treatment and the presence of social support structures for positive outcomes.

The median length of hospital stay for hepatitis A cases included in this study was largely influenced by clinical outcomes. It is worrisome that patients who died under care had significantly shorter hospital stays meaning that these patients likely presented for care at a very late stage of infection. If patients did not die as a result of hepatitis

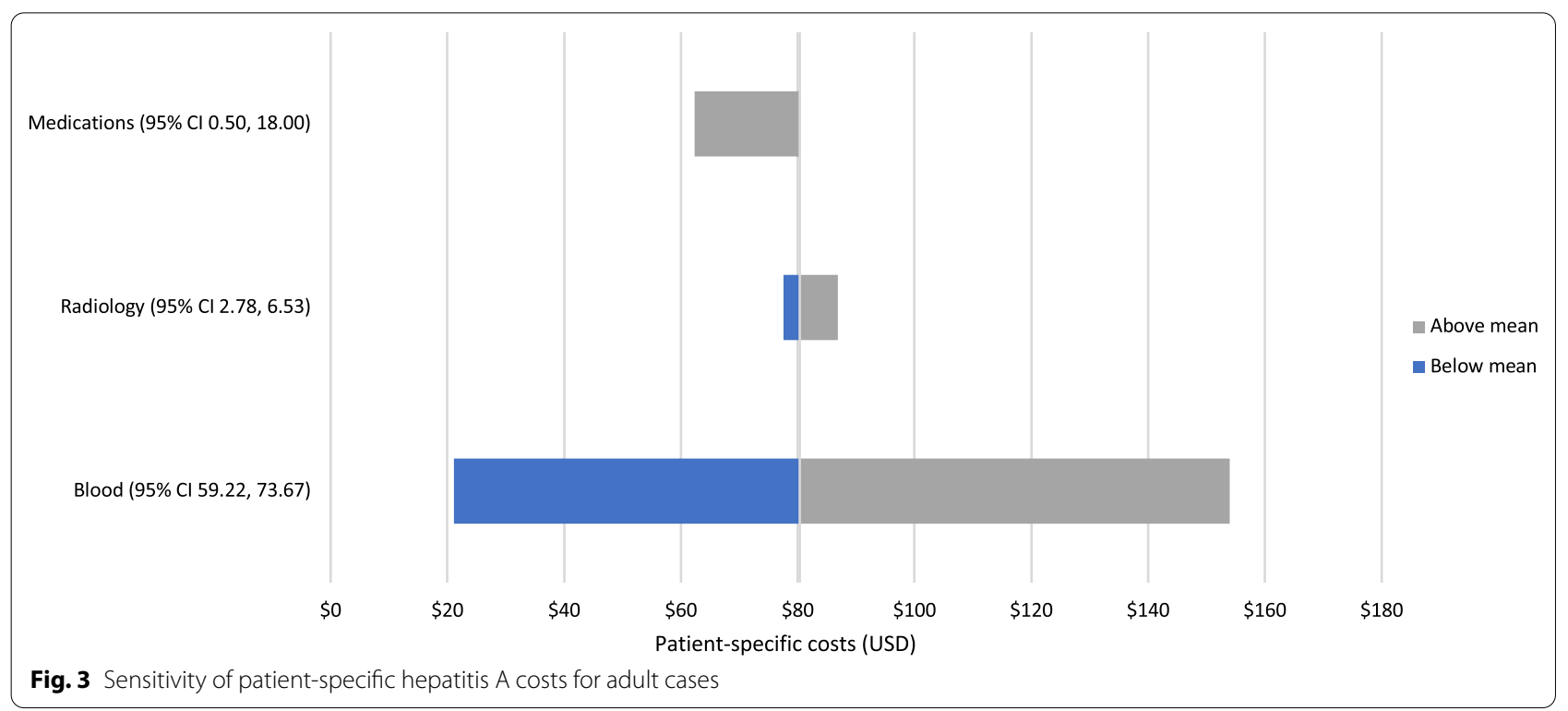



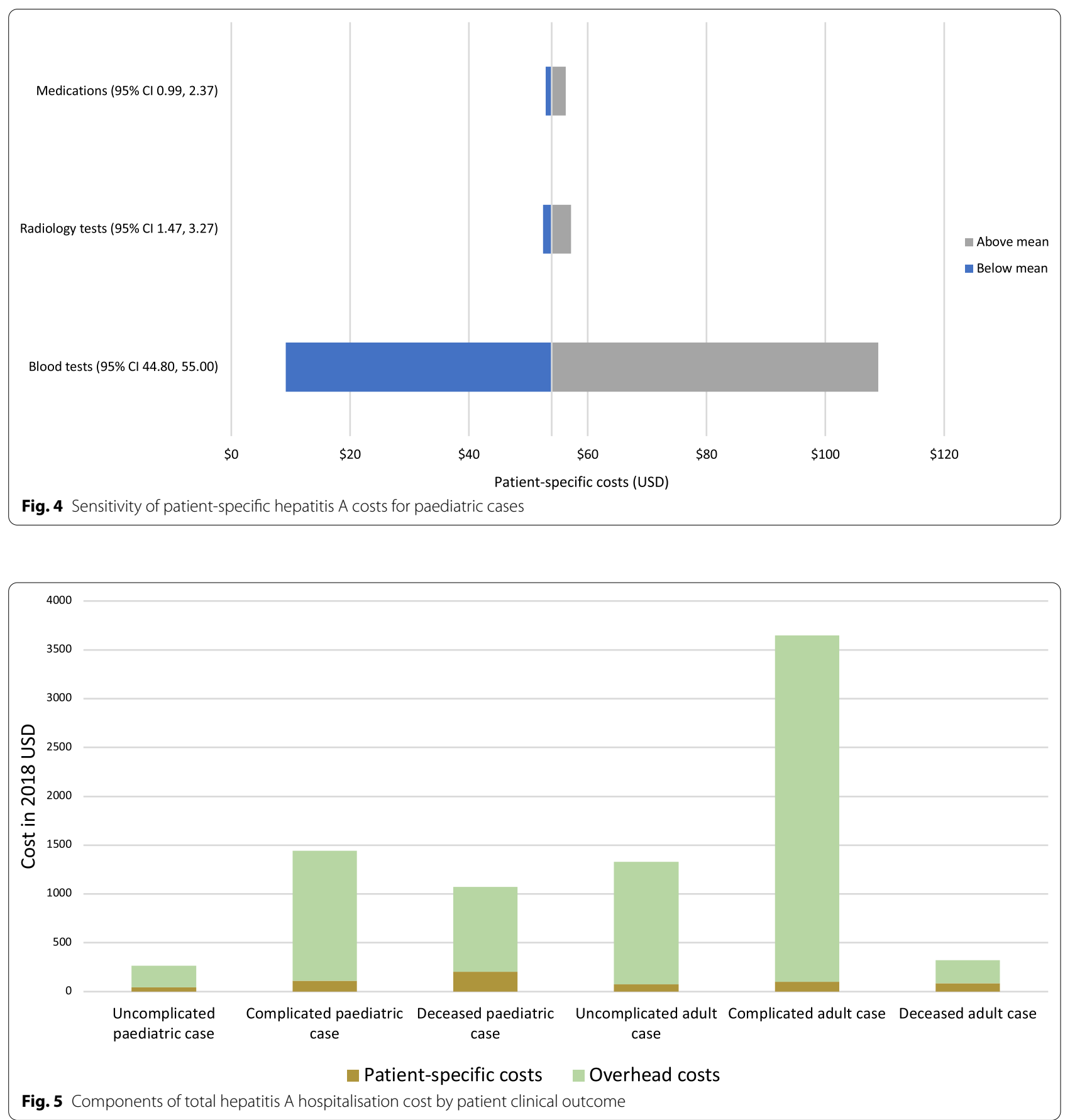

A infection, they required significant resources for case management and treatment.

Blood tests were the main cost driver for patientspecific hepatitis A costs in both adult and paediatric patients, with an average of 3 blood panels ordered per hepatitis A case. The mean total cost per hepatitis A hospitalisation was $\$ 1,935.41$ for adult patients and
\$563.06 for paediatric patients. The overhead costs dictated by the length of hospital stay were the main driver of total cost per hepatitis A hospitalisation. Notably, a large majority of adult and paediatric patients included in this study paid a nominal daily fee for hospitalisation and the government was responsible for paying $>90 \%$ of the cost of treatment in more than $75 \%$ of cases included in this study. Further work should include 
an analysis of the impact of hepatitis A hospitalisation costs on the national health budget.

At large, the patient-specific hepatitis A cost estimates presented in this study are likely underestimates of the true costs of care. This folder review was conducted at tertiary level facilities, therefore, the study was unable to capture costs incurred for care at the primary level, which was utilised by approximately $70 \%$ of patients before presenting for tertiary care. The folder review also did not capture costs at non-tertiary hospitals, where patients (particularly severe patients who died under care at GSH and $\mathrm{RCH}$ ) may have sought care before presenting at the tertiary levels facilities included in this study. Additionally, the adoption of a provider's perspective in this study led to the exclusion of costs incurred by patients for care and did not allow for the opportunity costs of accessing care including out-of-pocket payments and loss of productivity. Lastly, the folder review did not include additional costs of providing prophylaxis to close contacts of hepatitis A cases with HAV vaccine or immunoglobulin according to clinical guidelines in South Africa [20].

Additional limitations of this study include that the underlying epidemiological characteristics of the study population were not well described as comorbidities were not well documents and not all patients were tested for HIV, hepatitis B, or hepatitis $\mathrm{C}$ at the time of admission. Information on hepatitis A risk factors such as housing, sanitation, and water source were also not routinely reported in patient folders. Patients presenting to the included tertiary facilities cannot be considered representative of the general South African population, however, the clinical outcome and cost data collected in this study provides a better local context than is currently represented in published literature.

Notwithstanding the noted limitations, this is the first study to describe the clinical severity and costs of care for hepatitis A cases in South Africa. The study highlights the notable severity of hepatitis A infection experienced by many patients in South Africa and the high burden of cost on the national health budget for case management and treatment of the disease. This study is part of an ongoing body of work to determine the costeffectiveness of introducing hepatitis A vaccines into the South African Expanded Programme on Immunization. The ongoing work includes a dynamic model to estimate the epidemiological and economic outcomes for different hepatitis A vaccination strategies in the country.

\section{Conclusion}

More than 1 in 10 hepatitis A cases included in this study developed complicated hepatitis A or died as a result of infection. Given the severity of clinical outcomes and high costs associated with hepatitis A hospitalisation, it is important to consider the introduction of hepatitis $\mathrm{A}$ immunisation in the national immunisation program in South Africa to avert future morbidity, mortality, and significant healthcare spending from the national health budget.

\section{Risks and benefits}

As this was a retrospective study, patient care was not affected. It is hoped that this study will help to highlight the significant burden that acute hepatitis A places on the population and will motivate for inclusion of the vaccine on a national scale.

\section{Abbreviations}

ALP: Alkaline phosphatase; ALT: Alanine aminotransferase; AST: Aspartate aminotransferase; CDC: Centres for Disease Control and Prevention; EPI: Expanded program on immunization; GSH: Groote Schuur Hospital; HAV: Hepatitis A virus; IgG: Immunoglobulin G; IgM: Immunoglobulin M; INR: International normalised ratio; RCH: Red Cross War Memorial Children's Hospital; WHO: World Health Organization.

\section{Supplementary Information}

The online version contains supplementary material available at https://doi. org/10.1186/s12879-021-06993-w.

Additional file 1: Table S1. Mean and median lengths of hospitalisation by patient outcome.

Additional file 2: Table S2. Unit counts and cost (2018 USD) for patientspecific hepatitis A items.

\section{Acknowledgements}

We would like to thank Dr Christine Richie Mulligan for collecting the data for this retrospective folder review.

\section{Authors' contributions}

JP, SC, SPS, BMK, and RM conceived this study. JP developed the study protocol with the help of SC and RM. JP implemented the research under the supervision of SC and RM. JP conducted all analyses, developed this manuscript, and is the guarantor of this research. All authors read and approved the final manuscript.

\section{Funding}

Funding for this research was provided by the Vaccines for Africa Initiative (VACFA) and the Department of Science and Innovation and the National Research Foundation (NRF). Any opinion, finding, and conclusion or recommendation expressed in this material is that of the authors and the NRF does not accept any liability in this regard.

\section{Availability of data and materials}

The datasets generated and/or analysed during the current study are not publicly available due to ongoing research but are available from the corresponding author upon reasonable request.

\section{Declarations}

Ethics approval and consent to participate

As this is a retrospective study, patient care or management was not be affected. Individual patients consent was waived by the superintendents of each healthcare facility. The study was approved by the University of Cape Town's Research Ethics Committee and research clearance was granted by the two facility research committees (GSH HREC 485 and RCH's RCC 153). All 
methods were performed in accordance with the relevant ethics guidelines and regulations.

\section{Consent for publication}

Not applicable.

\section{Competing interests}

All authors declare that they have no competing interests.

\section{Author details}

'Division of Epidemiology and Biostatistics, School of Public Health and Family Medicine, University of Cape Town, Cape Town, South Africa. ${ }^{2}$ Vaccines for Africa Initiative, School of Public Health and Family Medicine, University of Cape Town, Cape Town, South Africa. ${ }^{3}$ Division of Health Economics, School of Public Health and Family Medicine, University of Cape Town, Cape Town, South Africa. ${ }^{4}$ Modelling and Simulatio Hub Africa, Department of Statistical Sciences, University of Cape Town, Cape Town, South Africa. ${ }^{5}$ Division of Medical Microbiology, Institute of Infectious Disease and Molecular Medicine, University of Cape Town, Cape Town, South Africa. ${ }^{6}$ National Health Laboratory Service, Groote Schuur Hospital, Cape Town, South Africa. ${ }^{7}$ Division of Medical Virology, Department of Pathology, University of Cape Town, Cape Town, South Africa. ${ }^{8}$ Department of Paediatrics and Child Health, Red Cross War Memorial Children's Hospital, University of Cape Town, Cape Town, South Africa. ${ }^{9}$ Department of Medicine, Groote Schuur Hospital, University of Cape Town, Cape Town, South Africa.

Received: 3 July 2021 Accepted: 15 December 2021

Published online: 11 January 2022

\section{References}

1. World Health Organization. WHO position paper on hepatitis A vaccines_June 2012. Wkly Epidemiol Rec. 2012. 87(28/29).

2. Mazanderani AH, Motaze VN, McCarthy K, Suchard M, du Plessis NM Hepatitis A virus seroprevalence in South Africa-estimates using routine laboratory data, 2005-2015. PLoS ONE. 2018. https://doi.org/10.1371/ journal.pone.0216033.

3. Enoch A, Hardie DR, Hussey GD, Kagina BM. Hepatitis A seroprevalence in the Western Cape Province, South Africa. Are we in epidemiological transition? S Afr Med J. 2019;109:314-8. https://doi.org/10.7196/SAMJ. 2019.v109i5.13410.

4. Solomons RS, Rabie H, Nel ED, Cotton MF. An overview of hepatitis A at Tygerberg Children's Hospital. S Afr Med J. 2008;2(2):43-5.

5. Patterson J, Hussey HS, Abdullahi LH, Silal S, Goddard L, Setshedi M, et al. The global epidemiology of viral-induced acute liver failure: a systematic review protocol. BMJ Open. 2019. https://doi.org/10.1136/bmjop en-2019-029819.

6. Anonychuk AM, Tricco A, Bauch CT, Pham B, Gilca V, Duval B, et al. Costeffectiveness analyses of hepatitis $A$ vaccine: a systematic review to explore the effect of methodological quality on the economic attractiveness of vaccination strategies. Pharmaeconomics. 2008;26:17-32. https:// doi.org/10.2165/00019053-200826010-00003.

7. Sartori AM, de Soarez PC, Novaes HM. Cost-effectiveness of introducing the 10-valent pneumococcal conjugate vaccine into the universal immunisation of infants in Brazil. J Epidemiol Community Health. 2012;66:2107. https://doi.org/10.1136/jech.2010.111880.

8. Ellis A, Rüttimann RW, Jacobs J, Meyerhoff AS, Innis BL. Cost-effectiveness of childhood hepatitis A vaccination in Argentina: a second dose is warranted. Rev Panam Salud Publica. 2007. https://doi.org/10.1590/s102049892007000500002.

9. Centers for Disease Control and Prevention. Hepatitis A, Acute 2019 Case Definition. Atlanta, GA: Centers for Disease Control and Prevention; 2019. Report No.: 18-ID-07.

10. Bhatt H, Rao GS. Management of acute liver failure: a pediatric perspective. Curr Pediatr Rep. 2018;6(3):246-57. https://doi.org/10.1007/ s40124-018-0174-7.

11. Shin EC, Jeong SH. Natural history, clinical manifestations, and pathogenesis of hepatitis A. Cold Spring Harb Perspect Med. 2018. https://doi.org/ 10.1101/cshperspect.a031708.
12. Squires JE, McKieran $P$, Squires $\mathrm{RH}$. Acute liver failure: an update. Clin Liver Dis. 2018;22(4):773-805. https://doi.org/10.1016/j.cld.2018.06.009.

13. Arshad MA, Murphy N, Bangash MN. Acute liver failure. Clin Med. 2020;20(5):505-8. https://doi.org/10.7861/clinmed.2020-0612.

14. StataCorp, inventorStata Statistical Software: Release 16. USA2019.

15. Husereau D, Drummond M, Petrou S, Carswell C, Moher D, Greenberg $D$, et al. Consolidated health economic evaluation reporting standards (CHEERS) — explanation and elaboration: a report of the ISPOR Health Economic Evaluations Publication Guidelines Good Reporting Practices Task Force. Value Health. 2013;16(2):231-50. https://doi.org/10.1016/j.jval. 2013.02.002.

16. Walker DG, Hutubessy R, Beutels P. WHO Guide for standardisation of economic evaluations of immunization programmes. Vaccine. 2010;28(11):2356-9. https://doi.org/10.1016/j.vaccine.2009.06.035.

17. National Health Laboratory Service. NHLS State Price List 2018. South Africa: National Health Laboratory Service Republic of South Africa; 2018.

18. National Department of Health. Uniform Patient Fee Schedule. South Africa: Department of Health Republic of South Africa; 2018.

19. X-Rates. Monthly average 2018 2021. https://www.X-rates.com/average/? from $=Z A R \&$ to $=U S D \& a m o u n t=1 \&$ year $=2018$.

20. de Jong G, Schoub B, Blumberg L. Guidelines for the Control of Hepatitis A in South Africa. South Africa: National Institiue of Communicable Disease; 2007.

\section{Publisher's Note}

Springer Nature remains neutral with regard to jurisdictional claims in published maps and institutional affiliations.
Ready to submit your research? Choose BMC and benefit from:

- fast, convenient online submission

- thorough peer review by experienced researchers in your field

- rapid publication on acceptance

- support for research data, including large and complex data types

- gold Open Access which fosters wider collaboration and increased citations

- maximum visibility for your research: over 100M website views per year

At BMC, research is always in progress.

Learn more biomedcentral.com/submissions 